\title{
Forum
}

Members of the association are invited to submit letters, typed and double-spaced, commenting on articles published in $P M L A$ or on matters of general scholarly or critical interest. Footnotes are discouraged, and letters of more than one thousand words will not be considered. Decision to publish and the right to edit are reserved to the editor, and the authors of articles discussed will be invited to respond.

\section{Interpreting Shakespeare's Sonnets}

To the Editor:

Adena Rosmarin's "explicitly purposeful" account of Shakespeare's Sonnets, "Hermeneutics versus Erotics: Shakespeare's Sonnets and Interpretive History" (100 [1985]: 20-37), ends up perpetuating the very reading of the Sonnets it establishes as traditional. Instead of resolving her paradoxical characterization of the Sonnets as "sincere" and "artificial," Rosmarin sustains it by attributing it to the sonnets' dual identity as heartfelt love utterances and artful poems. By first implanting this reading in critical history and then ratifying it with critical theory, the article secures what it demonstrates has been entrenched for almost two centuries.

Why endorse what needs no endorsing? With Rorty's pragmatist critic, Rosmarin might answer, because such an explanation is useful to our understanding and appreciation of the text. We seek "the explanation that best explains the literary text, most fully unfolding its distinctive aesthetic richness, heuristic power, and conceptual challenge" (32). If this unfolding occurs when the sonnets are read as both sincerely spoken and artificially written, her explanation is no doubt useful.

Curiously, however, only in discussing the sonnets as artificial does Rosmarin attempt such an unfolding. Her reading of sonnet 138 , for example, displays the bold gyrations of sound and sense by which the sonnet releases itself from referential fidelity and asserts its semantic independence. But what is the sincere counterpart to this irresponsible tropological writing? Indeed, the concept of sincerity seems strangely inapplicable to the exchanges described in "When my love swears she is made of truth / I do believe her though I know she lies."

The problem in sonnet 138 is not that words belie their speakers' feelings but rather that they are true to the speakers' mutual desire (to lie together): "Therefore I lie with her, and she with me, / And in our faults by lies we flattered be." At issue, then, is the correspondence not between words and feelings but between words and desire, or will, the term the collection favors. That correspondence cannot sensibly be judged sincere or insincere, for will speaks to realize rather than reveal itself, an attempt that not improperly involves concealment, misrepresentation, and perversion of the truth.
In a sense, willful speech is always sincere, always true to itself, though its very fidelity to self-interested desire might well preclude any such claim.

It is unclear on what grounds Rosmarin can single out the sincere strain from the multiple artificial ones. Unless we assume we know what sincerity looks like before the poet reveals it, how can we recognize it? In the line Rosmarin takes as a model of Renaissance sincerity, Sidney's "'Foole,' said my muse to me, 'looke in thy hearte and write,"' what authorizes singling out heart as the site of feeling from heart as the site of appetite or will, for example? And what is to prevent an Elizabethan ear from hearing art as well as heart if the $h$ was, as phonologists agree, almost silent? (This particular conflation throws into question the divisibility of the very terms under discussion.) Though Rosmarin maintains that spoken words are not vexed by the tropological ambiguities besetting written ones, Elizabethan rhetorics classified the tropes she discusses as auricular figures, figures of sound.

The issue of sincerity is inapplicable not only to sonnet 138 but to the psychological and discursive circumstances of the whole collection. Rationalization (35), self-flattery (62), self-deception (93), conscious madness (147), perjury (152) all issue from a torn and conflicted self, too doubled up to be gauged by as single-minded and univocal a principle as sincerity. For the very possibility of such a pure principle, like fair itself, is challenged by the ambivalence of the sonnets to the young man and confuted by the negations of those to the dark lady. That no satisfactory equivalent for sincerity can be found in Renaissance rhetorics casts further doubt on the relevance of this principle. Rosmarin substitutes plain speech, but plain speech is itself an artificial style. (Consider Berowne's renunciation of "Taffeta phrases, silken terms precise" for equally artificial "russet years and honest kersey noes" [Love's Labour's Lost 5.2.406, 413].) She also proposes decorum, yet decorum appeals to outer circumstances of composition and delivery irrelevant to a principle accountable only to private evaluation.

To dispute the appropriateness of sincerity to the Sonnets is not to opt for artifice but to question the 
present viability or usefulness of the dichotomy. As Rosmarin herself reveals, it is in response to the late eighteenth-century need to read the Sonnets as psychologically sincere as well as historically authentic that the merely artificial is brought into play as a means of shaping, regulating, and maintaining the sincere. The sincerity-artificiality antithesis thus serves to identify Shakespeare with certain desirable traits and to dissociate him from objectionable ones.

Rosmarin's interpretive history is useful in treating criticism of the Sonnets not as an account to be set aside or passed through before confronting the sonnets themselves but as an account on which that confrontation depends. Yet her traditional terms no longer usefully characterize that confrontation, for the dichotomy misrepresents our current interest in the discursive and psychological schismatics of the Sonnets. Furthermore-and this may be the same thing-it trivializes the impact of the deconstructive, not to mention pragmatic, challenges that enable the "inventional dynamics" of her account.

If such an account no longer satisfies us, we might prefer an interpretive history that does not settle us more comfortably into the traditional interpretive position-an unsettling history that would not resituate us where we have been but rather question the necessity of our ever having been there. More conscious of its own historical status, such a history might begin by asking why at a certain point in the early nineteenth century it became necessary to interpret the Sonnets, to interpret poetry, as sincere and artificial. This question gives rise to a still more radical one: Why at that point did it become necessary to give and publish interpretations at all? For the truly useful question Rosmarin's article tacitly poses is, Why did the interpretive history of the Sonnets not begin until almost two centuries after the work appeared?

\section{Margreta de Grazia \\ University of Pennsylvania}

\section{Reply:}

De Grazia's response illustrates our need for a theory of interpretive history. Her misunderstanding of the purpose and dynamics of writing interpretive histories-she thinks that solving a problem "secures" it, that plotting a history perpetuates it-issues from the traditional theoretical assumptions that surface in her conclusion. And these assumptions, in turn, engender the multiple misreadings that inhabit the body of her response.

To begin with these misreadings. First, I cite Sidney's famous prescription-that in one's "heart" one finds "art"-because its punning irony enacts my thesis: that "hermeneutics" and "erotics" are paradoxically one. De
Grazia, however, wonders how I "can single out the sincere strain." The answer is that I cannot and do not. The impossibility of doing so is my point. Second, according to de Grazia, I "maintain that spoken words are not vexed by the tropological ambiguities besetting written ones." As anyone who has read the Phaedrus or my essay knows, the idea is Plato's, not mine. I presume only to analyze its consequences. Third, de Grazia observes that "plain speech is itself an artificial style." I quite agree: "seeming artlessness requires perhaps the greatest art" (23). Fourth, she argues that correspondence should be construed in terms of "will," for "willful speech is always sincere, always true to itself." Again, one must agree-especially when the maker of these "sugred Sonnets" is named "Will"-and I do agree: "when a sonneteer speaks eloquently he is speaking in character or, as we say, sincerely" (30).

What is interesting is that de Grazia has misread not simply but significantly: consistently (mis)taking my topics for my tools, consistently taking my presumed tools as her topics. This displacement happens because de Grazia's own interpretive tools and criteria-note that she deems tropological writing "irresponsible"are precisely those that I analyze, namely, those of post- 1800 criticism and theory. Her critique thus constitutes an inadvertent self-critique, its assumptions "found" in my discourse and contested in her own. More important, however, are the assumptions about interpretive histories that remain unfound and uncontested, those that impel and inform her concluding questions.

But first, an answer. It is well known that Shakespeare's sonnets were a Romantic obsession because their generically "personal" rhetoric made them seem the key to Shakespeare's heart (20). A less well known reason was the publication in 1780 of Edmund Malone's Quarto-based edition, which supplanted John Benson's pirated edition, first published in 1640. Benson's editing, to say the least, was creative: eight sonnets, the dedication, and the 1609 title were removed; additional poems-some not by Shakespeare-were interwoven, and the recombinant results individually titled; other changes made the male beloved seem female. Thus, only with Malone's edition did the sonnets reacquire the story whose erotic enigma seemed at once to demand interpretation and to authorize "sincerity" and "artifice" as interpretive terms.

Now let us examine de Grazia's questions. They assume (1) that the first published text is a work's "appearance," (2) that this "appearance" is a self-evident and uniquely important textual origin, which the interpretive history interprets, (3) that the interpreting work is separate from the (temporally and logically prior) interpreted work, (4) that the interpretive history of the sonnets begins around 1800 and consists of "interpretations" (presumably critical essays or books), 